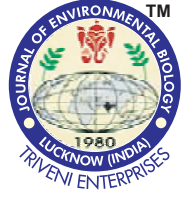

DOI : http://doi.org/10.22438/jeb/39/3/MRN-607

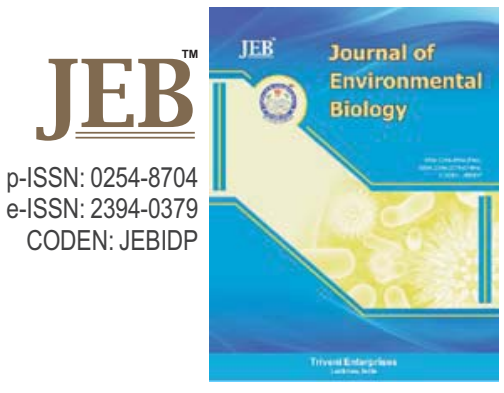

\title{
Microsatellite markers based characterization in advance breeding lines and cultivars of bread wheat
}

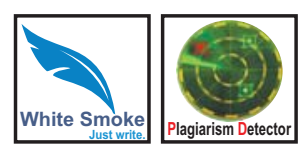

Authors Info

D. Phougat*, I.S. Panwar, M.S. Punia and S.K. Sethi

Department of Genetics and Plant Breeding, Chaudhary Charan Singh Haryana Agricultural University, Hissar-125 004, India

${ }^{*}$ Corresponding Author Email : divyaphougat786@gmail.com

Key words

Breeding lines

Genetic diversity

Microsatellite markers

Polymorphism

Wheat cultivars

Publication Info

Paper received : 23.05.2016

Revised received : 29.11 .2016

Re-revised received : 05.09.2017

Accepted : 07.09.2017

\begin{abstract}
\end{abstract}
Aim : Studying genetic diversity is useful for wheat breeding and production of more efficient wheat cultivars under changing climatic conditions. Forty-four diverse bread wheat genotypes were assessed for genetic diversity study using 70 microsatellite (SSRs) markers covering all three genomes.

Methodology : Genomic DNA of 44 genotypes was extracted using CTAB method and quality was checked by UV spectrophotometer and agarose gel electrophoresis. PCR amplification reaction was carried out and amplified products were resolved by horizontal electrophoresis. Bands were scored and matrix was used to calculate the similarity genetic distance. Phenotypic data was subjected to Euclidean cluster analysis for estimation of genetic divergence and grouping of genotypes into clusters.

Results : A total of 181 alleles were detected and the number of alleles per locus ranged from 1-5 with an average of 2.6 alleles per locus. The overall size of PCR products amplified ranged from 100-475 bp. Significant differences in allelic diversity among various microsatellite loci were seen. The SSR primers, xgwm 428, xbarc 1165, wmc 477, psp 3071, xcfa 2129 , xgwm 18, xgwm 234 and xbarc 359 amplified single allele, while the primers xgwm 46, xgwm 334 and wmc 517 amplified five alleles. The similarity coefficients among all the genotypes ranged from 0.62 to 0.81 . The cluster tree analysis based on

Advance breeding lines and cultivars of bread wheat were

characterized both at phenotypic and molecular level

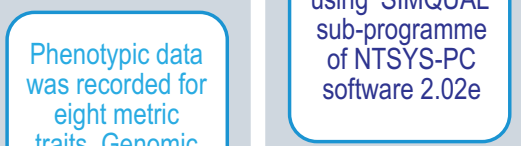

DNA of 44

genotypes was

isolated using

modifed CTAB method.
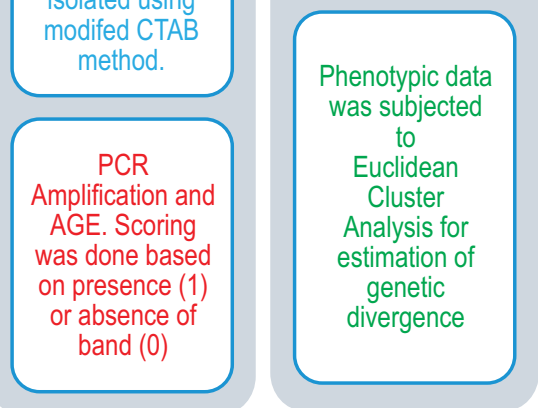

0/1 matrix was used to calculate the similarity genetic distance using 'SIMQUAL' sub-programme software 2.02 UPGMA following the software NTSYS PC led to grouping of 44 genotypes in different clusters in such a way that the genotypes within each cluster had higher similarity than between clusters.

Interpretation : The study ascertained that microsatellite markers can be exploited as a new generation tool in studying the polymorphism and genetic diversity among cultivars and further, selection of parental combinations for initiating breeding programs. 


\section{Introduction}

The knowledge of genetic diversity can be used as an important tool for improving quantitative traits (Huang et al., 2002). This knowledge can in turn become a valuable source for further improvement of modern cultivars. The differences that distinguish one cultivar from another are encoded in the crop's genetic material and is passed to each generation. Bread wheat (Triticum aestivum) is a hexaploid species with three sets of basic chromosomes number ( $x=7$ and $6 x=2 n=42)$, and the three genomes originating from natural hybridization of related species.

Globally, India is the second largest wheat producer after China and recorded a production of 93.50 million ton from an area of 30.23 million ha with a productivity of $30.93 \mathrm{q} \mathrm{ha}^{-1}$ (Anonymous, 2016). World population is expected to increase from around 6 billion now to around 8 billion by 2020 , and more than $95 \%$ of the additional population will be in the developing countries. The agricultural sector in developing countries like India and Pakistan needs increased crop production to fulfill the demand and to occupy a pivotal position in agricultural crop production and hence, contributes a lot to the gross domestic product.

Since a narrow genetic base of germplasm is highly vulnerable to biotic and abiotic stresses, diversity is important for crop breeding and its assessment provide keys to disclose ways to combat the threats of environmental fluctuations (Khan et al., 2015). Molecular markers are environment insensitive, they provide most suitable tool for evaluation of genetic material. DNA has no effect of environmental conditions (Cifci and Yagdi, 2012; Abouzied et al., 2013; Malik et al., 2013). Therefore, assessment of genetic diversity at the molecular level is more consistent than at the phenotypic level. Presently, several kinds of DNA based molecular markers are available. Use of genetic markers not only provides information about genetic diversity but also helps in understanding the genetic control of quantitative characters. They can provide detailed characterization of genetic resources (Zhang et al., 2009; Mir etal., 2012).

Simple sequence repeats (SSRs) have been extensively used in wheat due to their high level of polymorphism, codominant inheritance and abundant distribution in the wheat genome (Roder et al., 1995; Parker et al., 2002). It has also been found that they show a much higher level of polymorphism and information than any other marker system in wheat crop (Ma et al., 1996; Bryan et al., 1997). Till date, more than 4000 SSR markers have been developed and used in genetic mapping studies of wheat (Han et al., 2015). SSR markers also play an important role in cultivar identification and genetic diversity studies (Hao et al., 2011). In the present study, both phenotypic as well as molecular data were used to assess inherent genetic diversity of the selected bread wheat advance breeding lines and cultivars.

\section{Materials and Methods}

The present study was carried out at Research Farm of Department of Genetics and Plant Breeding, Chaudhary Charan Singh Haryana Agricultural University, Hisar, a semi-tropical region of North Western Plain Zone of India. Plant material consisted of 44 bread wheat genotypes (38 cultivars and 6 advance breeding lines) (Table 1), grown during 2014-15 rabi crop season in a randomized block design with three replications. Each genotype was sown in $2.5 \mathrm{~m}$ long paired row plots with rowto- row distance of $20 \mathrm{~cm}$ and plant-to-plant distance of $10 \mathrm{~cm}$.

Phenotypic analysis of genetic diversity : Observations were recorded on five randomly chosen plants of each genotypes in each replication for eight metric traits, namely, days to heading, plant height $(\mathrm{cm})$, tiller no per plant, grains per ear, 1000-grain weight $(\mathrm{g})$, biological yield per plant $(\mathrm{g})$, harvest index (\%) and grain yield per plant $(\mathrm{g})$. Statistical analysis of data was carried out by the method of Panse and Sukhatme (1978). Genetic divergence was estimated by Euclidean cluster analysis and grouping of the genotypes into clusters was done using Ward (1963) method.

Genomic DNA isolation : Genomic DNA was isolated from each genotype using CTAB method of Saghai-Maroof et al. (1984). To remove RNA contamination, DNA samples were treated with $1 \mu \mathrm{l}$ of RNase A solution (10 $\mathrm{mg} \mathrm{ml}^{-1}$ ) per $50 \mu \mathrm{l}$ of DNA sample. Quality of DNA samples was checked both by UV-spectrophotometer and on agarose gel electrophoresis. Using spectrophotometer, the ratio of the absorbance at $260 \mathrm{~nm}$ and $280 \mathrm{~nm}$ was noted. PCR amplified DNA fragments were resolved by submerged horizontal electrophoresis in $2.5 \%(\mathrm{w} / \mathrm{v})$ agarose gels. PCR amplified products were viewed under UV light $(350 \mathrm{~nm}$ ) fluorescence and photographs were taken by gel documentation system.

PCR amplification conditions : PCR amplification conditions were optimized with respect to concentration of template DNA, primers, $\mathrm{MgCl}_{2}$, Taq DNA polymerase and annealing temperature.

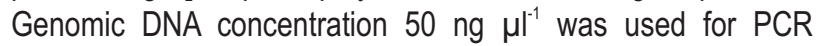
amplification, which was carried out in Benchtop thermocycler (programmable thermal cycler from BIORAD ${ }^{\mathrm{TM}}$ INTERNATIONAL).

Allele scoring : SSR amplification profiles were scored visually, based on the presence (taken as 1) or absence (taken as 0 ) of bands for each wheat genotype. Only clear and unambiguous bands were scored. The size (in nucleotide base pairs) of amplified bands was determined based on its migration relative to standard molecular size marker (100 kb).

Molecular data analysis : The 0/1 matrix was used to calculate the similarity genetic distance using 'SIMQUAL' sub-programme of NTSYS-PC software 2.02e (numerical taxonomy and 
Table 1 : Pedigree of bread wheat advance breeding lines and cultivars used to study genetic diversity

\begin{tabular}{|c|c|c|c|}
\hline Genotypes & Pedigree & Genotypes & Pedigree \\
\hline DPW $621-50$ & $\begin{array}{l}\text { KAUZ//ALTAR84/AOS/3/ } \\
\text { MILAN/KAUZ/4/HUITES }\end{array}$ & WH 1138 & PBW65*2/PASTOR \\
\hline HD 2967 & ALD/CUC//URES/HD2160/HD2278 & WH 1129 & $\begin{array}{l}\text { CS/TH.CS//3*PVN/3/MIRLO/B } \\
\text { UC/4/MILAN/5/TILHI }\end{array}$ \\
\hline Tobari & TZZP/AN64A & DBW 88 & $\begin{array}{l}\text { KAUZ/ALTAR84//ADS/3/MIL } \\
\text { AN/KAUZ/4/HUITES }\end{array}$ \\
\hline WH 1080 & PRL/2*PASTOR & HD 3086 & DBW14/HD2733//HUW468 \\
\hline DBW 17 & $\begin{array}{l}\text { CMH79A.95/3*CN079//RA } \\
\text { J3777 }\end{array}$ & WH 1179 & $\begin{array}{l}\text { OASIS/SKAUZ//4*BCN/3/3* } \\
\text { PASTOR }\end{array}$ \\
\hline PBW 550 & WH594/RAJ3856//W485 & WH 1124 & MUNIA/CHTO//AMSEL \\
\hline Aus 15854 & - & DBW 71 & PRINIA/UP2425 \\
\hline WH 1021 & $\begin{array}{l}\text { ALD/CUC//URES/HD2160/ } \\
\mathrm{Hd} 2278\end{array}$ & DBW 90 & HUW468/WH730 \\
\hline WH 542 & JUPATECO/BLUEJAYI/URES & PBW 343 & $\begin{array}{l}\text { ND/NG1944//KAL//BB/3/YAC } \\
\text { O's'/4/NEE5's' }\end{array}$ \\
\hline Veery's & $\begin{array}{l}\text { KAVKAZ/BUHO'S'//KAL } \\
\text { YANSONA/BLUEBIRD }\end{array}$ & WH 157 & NP876/S308//CNO/8156 \\
\hline WH 730 & CPAN2092/IMPROVED LOK 1 & KRL 210 & PBW65/2*PASTOR \\
\hline Raj 3765 & HD2402/VL639 & WH 1164 & RL6043/4*NAC//2*PASTOR \\
\hline Raj MR-1 & J24/Aus15854 & HD 2329 & $\begin{array}{l}\text { HD1962/E4870/3/K65/5/SKA/6/ } \\
\text { Up262 }\end{array}$ \\
\hline WH 595 & PRL6045/NAC76 & WH 1098 & TILHI/PASTOR \\
\hline WH 147 & $\begin{array}{l}\text { PJ SIB/P14//KT54B/3/C286/ } \\
\text { C273/4/S339/PV-18 }\end{array}$ & WH 1182 & $\begin{array}{l}\text { KLDR/PEWIT1//MILAN/ } \\
\text { DUCULA }\end{array}$ \\
\hline WH 711 & ALD'S'/HUAC//HD2285/3/HFW-17 & WH 416 & WH147/UP368 \\
\hline WH 1105 & MILAN/S87230//BABAX & DBW 16 & Raj3765/WR484//HUW468 \\
\hline WH 283 & HD1981/RAJ821 & WH 1185 & SONALIKA/RAJ3777 \\
\hline WH 1081 & PBW65/2*PASTOR & P-5-3 & $\begin{array}{l}\text { Registered genetic stock with } \\
\text { NBPGR (Ic296709) }\end{array}$ \\
\hline WH 1142 & CHEN/Ae.Sq.(TAUS)//FCT/3/2*WEAVER & Naphal Selection & Indian Landrace \\
\hline WH 1025 & C591/PBW231 & Atlas 66 & $\begin{array}{l}\text { FRONDOSO/REDHART3// } \\
\text { NOLL28 }\end{array}$ \\
\hline C 306 & REGENT1974/3*CHZ//*2C599/3/119/C281 & WH 712 & TRAP\#1/BBW//PFAU \\
\hline
\end{tabular}

multivariate analysis system programme) (Rohlf, 2000). Dendrogram was constructed by using distance matrix by the unweighted pair-group method with arithmetic average (UPGMA) sub-programme of NTSYS-PC. 2D and 3D Principal component analyses were performed.

\section{Results and Discussion}

Assessment of genetic diversity at molecular level is more useful than at phenotypic level; but, together, they provide an additional source of information.

A set of 100 microsatellite primer pairs covering all three wheat genomes and almost all the chromosomes were used, out of which 70 microsatellites were found polymorphic (Table 2). These primers were located almost equally on whole wheat genome i.e., on genome $A$ (chromosome 1, 2, 3, 4, 5, 6 and 7), B (chromosome 1, 2, 3, 4, 5 and 7) and D genome (chromosome 2, $3,4,5,6$ and 7$)$.
A total of 181 alleles were detected. The number of alleles per locus ranged from 1-5 with an average of 2.585 alleles per locus. This level of polymorphism was lower than the average of $3.2,5.7,8.44,10$ and 11.84 alleles per locus reported by Schuster et al., (2009); Sharma et al., (2010); Spanic et al., (2012); Nasab et al. (2013) and Zhang et al., (2006) respectively in their genetic diversity studies on bread wheat using microsatellite markers. The overall size of amplified PCR products ranged from 100-475 bp (Table 2). Mir et al. (2011) used 90 SSRs markers to examine genetic diversity in a collection of 263 Indian bread wheat cultivars and found that the SSR loci were equally distributed on all the three sub-genomes of wheat, although average number of alleles per locus differed (8 alleles/locus in A sub-genome; 7.15 alleles/locus in B sub-genome and 5.92 alleles/locus in D subgenome; ESM 2). Arora et al. (2014) assessed the status of genetic diversity among 319 Indian wheat varieties distributed across different agro-climatic regions of India using 30 primers, 
Table 2 : DNA amplification profile generated in advance breeding lines and cultivars of wheat using 70 polymorphic SSR primers

\begin{tabular}{|c|c|c|c|c|c|c|c|c|c|}
\hline Primer & $\begin{array}{l}\text { Chromosomal } \\
\text { location }\end{array}$ & $\begin{array}{l}\text { Size of } \\
\text { bands }\end{array}$ & $\begin{array}{l}\text { Total no. } \\
\text { of bands }\end{array}$ & $\begin{array}{l}\text { Annealing } \\
\text { temp }\left(C^{\circ}\right)\end{array}$ & Primer & $\begin{array}{l}\text { Chromosomal } \\
\text { location }\end{array}$ & $\begin{array}{l}\text { Size of } \\
\text { bands }\end{array}$ & $\begin{array}{l}\text { Total no. } \\
\text { of bands }\end{array}$ & $\begin{array}{l}\text { Annealing } \\
\text { temp }\left(C^{\circ}\right)\end{array}$ \\
\hline Xgwm 341 & $3 D$ & $150-425$ & 4 & 50.5 & cfa2153 & $1 \mathrm{~A}$ & $400-410$ & 2 & 60 \\
\hline barc 13 & $2 \mathrm{~B}$ & $200-325$ & 2 & 52 & xgwm 334 & $6 \mathrm{~A}$ & $200-430$ & 5 & 55 \\
\hline xgwm 325 & $6 \mathrm{D}$ & $100-200$ & 3 & 60 & xgwm428 & $7 D$ & 200 & 1 & 53 \\
\hline xgwm 102 & $2 \mathrm{D}$ & $175-200$ & 2 & 53 & xbarc1165 & $6 \mathrm{~A}$ & 300 & 1 & 61.3 \\
\hline xgwm 469 & $6 \mathrm{D}$ & $175-200$ & 2 & 52 & xgdm132 & $6 \mathrm{D}$ & $150-170$ & 2 & 54.6 \\
\hline xgwm 124 & $1 \mathrm{~B}$ & $200-325$ & 3 & 52 & xgwm397 & $4 \mathrm{~A}$ & 150 & 1 & 55 \\
\hline xgwm 666.2 & $5 \mathrm{~A}$ & $150-300$ & 4 & 51.8 & barc065 & $7 \mathrm{~B}$ & $100-120$ & 2 & 54 \\
\hline xgwm 400 & $2 \mathrm{~A}$ & $250-375$ & 3 & 52 & cfd50 & $2 D$ & $200-270$ & 3 & 60 \\
\hline xgwm 425 & $1 \mathrm{~B}$ & $150-175$ & 2 & 53 & $x c f d 7$ & $5 D$ & $380-420$ & 3 & 61 \\
\hline wmc 364 & $1 \mathrm{~B}$ & $200-225$ & 2 & 55 & xgwm368 & $4 \mathrm{~B}$ & $200-280$ & 2 & 56 \\
\hline xgwm 6 & $4 D$ & $175-225$ & 3 & 50 & xbarc1152 & 1B & $200-250$ & 2 & 64.8 \\
\hline xgwm 295 & $4 \mathrm{D}$ & $150-250$ & 4 & 49.5 & wmc477 & $2 \mathrm{~B}$ & 170 & 1 & 52 \\
\hline xgwm538 & $4 D$ & $100-200$ & 2 & 51 & psp3071 & $6 \mathrm{~A}$ & 200 & 1 & 52.5 \\
\hline xgwm 273 & $1 \mathrm{~B}$ & $175-425$ & 4 & 50 & cfd34 & $3 D$ & $100-400$ & 2 & 59.5 \\
\hline barc8 & $2 \mathrm{~B}$ & $250-275$ & 2 & 51 & xcfa2129 & $1 \mathrm{~A}$ & 120 & 1 & 54 \\
\hline xgwm374 & $2 \mathrm{~B}$ & $100-300$ & 5 & 52 & Xbarc012 & $3 A$ & $190-300$ & 4 & 57.3 \\
\hline xgwm 413 & $4 \mathrm{~B}$ & $100-125$ & 2 & 52.5 & psp2999 & $1 \mathrm{~A}$ & $130-150$ & 2 & 52 \\
\hline xgwm 46 & $7 \mathrm{~B}$ & $125-250$ & 5 & 49.5 & xbarc228 & $2 \mathrm{D}$ & $150-200$ & 3 & 57 \\
\hline psp 3000 & $1 \mathrm{~B}$ & $200-300$ & 2 & 51.5 & Xbarc24 & $6 \mathrm{~B}$ & $300-475$ & 4 & 60.5 \\
\hline barc 7 & $3 B$ & $300-325$ & 2 & 55 & xbarc359 & $3 \mathrm{~A}$ & 120 & 1 & 56.5 \\
\hline xgwm 498 & $1 \mathrm{~B}$ & $150-175$ & 2 & 50.5 & xbarc12 & $3 B$ & $200-240$ & 2 & 55 \\
\hline xgwm 359 & $2 \mathrm{~A}$ & $175-290$ & 4 & 49.5 & xgwm18 & $1 \mathrm{~B}$ & 190 & 1 & 51 \\
\hline xgwm 635 & $7 \mathrm{~A}$ & $125-150$ & 3 & 52 & xbarc084 & $3 B$ & $170-200$ & 2 & 52 \\
\hline xgwm 314 & $3 D$ & $100-175$ & 3 & 52 & wmc419 & $4 \mathrm{~B}$ & $200-220$ & 2 & 51 \\
\hline xgwm 566 & $3 B$ & $150-175$ & 2 & 52 & xbarc196 & $6 \mathrm{D}$ & $170-185$ & 2 & 51 \\
\hline xgwm 249 & $2 \mathrm{D}$ & $280-320$ & 2 & 53.5 & xgwm37 & $2 \mathrm{D}$ & $120-150$ & 2 & 50 \\
\hline wmc 312 & $2 \mathrm{~A}$ & $200-225$ & 2 & 52 & xgwm611 & $7 \mathrm{~B}$ & $140-180$ & 3 & 51 \\
\hline wmc517 & $7 \mathrm{~B}$ & $100-400$ & 5 & 55 & xgwm102 & $2 \mathrm{D}$ & $160-190$ & 2 & 50 \\
\hline wmc 527 & $3 B$ & $400-425$ & 4 & 57 & xgwm260 & $7 \mathrm{~A}$ & $280-450$ & 3 & 55 \\
\hline wmc 170 & $2 \mathrm{D}$ & $200-250$ & 3 & 56 & xgwm234 & $5 \mathrm{~A}$ & 200 & 1 & 50.5 \\
\hline gwm133 & $1 \mathrm{~B}$ & $100-140$ & 3 & 58 & wmc1 & $3 B$ & $180-200$ & 2 & 51 \\
\hline xgwm 617.2 & $6 \mathrm{~A}$ & $100-300$ & 4 & 50.7 & xbarc219 & $7 \mathrm{D}$ & $200-220$ & 2 & 58 \\
\hline xgwm 111.2 & $2 \mathrm{~B}$ & $135-300$ & 4 & 51.5 & xbarc310 & $3 A$ & $190-250$ & 3 & 56 \\
\hline xgwm 33 & $1 \mathrm{~A}$ & 145-195 & 3 & 55 & xbarc04 & $5 B$ & $100-120$ & 3 & 56 \\
\hline xgwm 513 & $4 \mathrm{~B}$ & 135-195 & 3 & 60.2 & cfa2135 & $1 \mathrm{~A}$ & $100-200$ & 3 & 55 \\
\hline
\end{tabular}

out of which 16 primers were found polymorphic; and could be used effectively for future breeding practices.

The present study also showed that SSR primer xgwm 428, xbarc 1165, wmc 477, psp 3071, xcfa 2129, xgwm 18, xgwm 234 and $x$ barc 359 generated least number of bands i.e., one while three primers namely xgwm 46, xgwm 334 and wmc 517 produced maximum number of bands i.e., five. The alleles revealed by markers showed a higher degree of polymorphism (Fig. 1). Significant differences in allelic diversity among various microsatellite loci have been found in present study which was also supported by the studies of other authors (Kumar et al., 2016, and Kara et al., 2017). Drikvand et al. (2015) assessed genetic diversity of some durum and bread wheat genotypes using 37 microsatellites and distinguished a total of 71 alleles (2-4 alleles per each locus with an average number of 2.36 alleles per locus).
The results of the present study along with other studies discussed above clearly demonstrate the utility of microsatellite markers in fast and high throughput fingerprinting of numbers of genotypes/ or germplasm collection for detecting polymorphism and estimation of genetic diversity.

The similarity coefficients between all genotypes ranged from 0.62 to 0.81 and averaged 0.71 . It showed the most closely related wheat genotypes were WH 1182 and WH 1124 and highest similarity index was 0.81 . On the contrary, most diverse genotypes were Tobari and HD 2967, with low similarity index of 0.62 (Fig. 2). While the average value of similarity coefficient was reported to be 0.48 by Drikvand et al. (2015), 0.54 by Yildirim et al. (2011) and 0.60 by Kara et al. (2017) in genetic diversity studies in wheat using SSR markers. Sharma et al. (2010) estimated similarity index of pair-wise comparisons on the basis of 10 


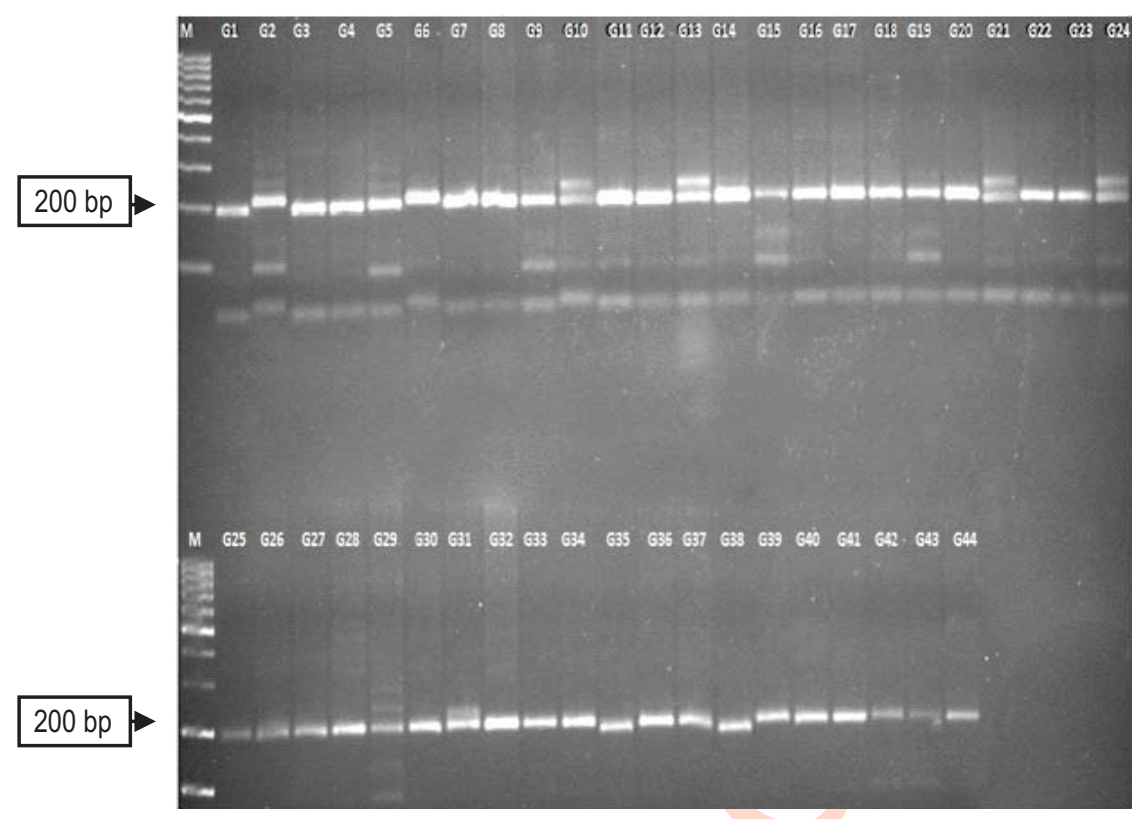

Fig. 1 : Electrophoretic pattern of advance breeding lines and cultivars in SSR analysis using primer xgwm 312, M-marker (100 kb standard ladder marker) and G1-G44 (Names are available in table 1)

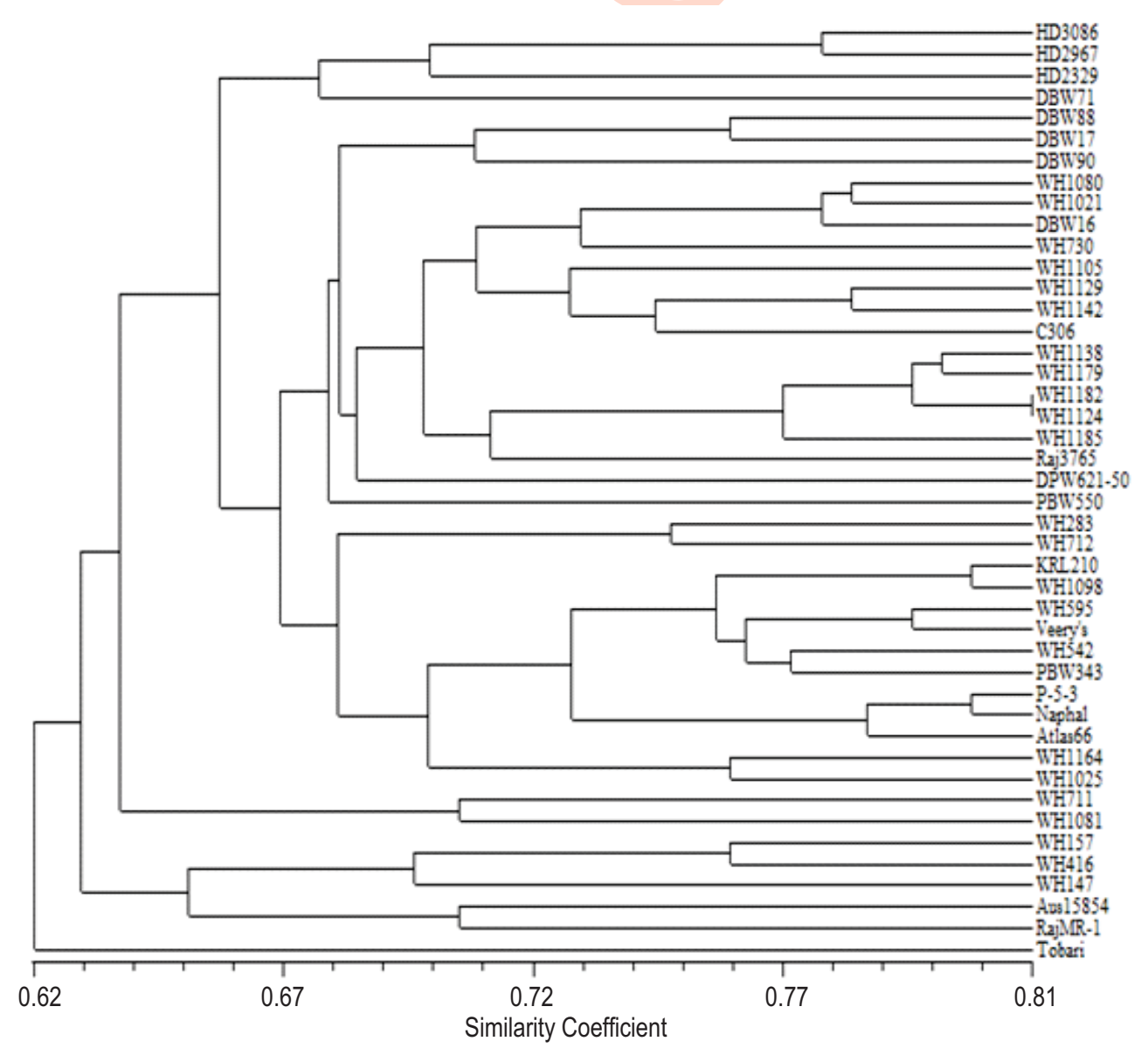

Fig. 2 : Dendrogram constructed with UPGMAclustering method among advance breeding lines and cultivars using SSR primers 


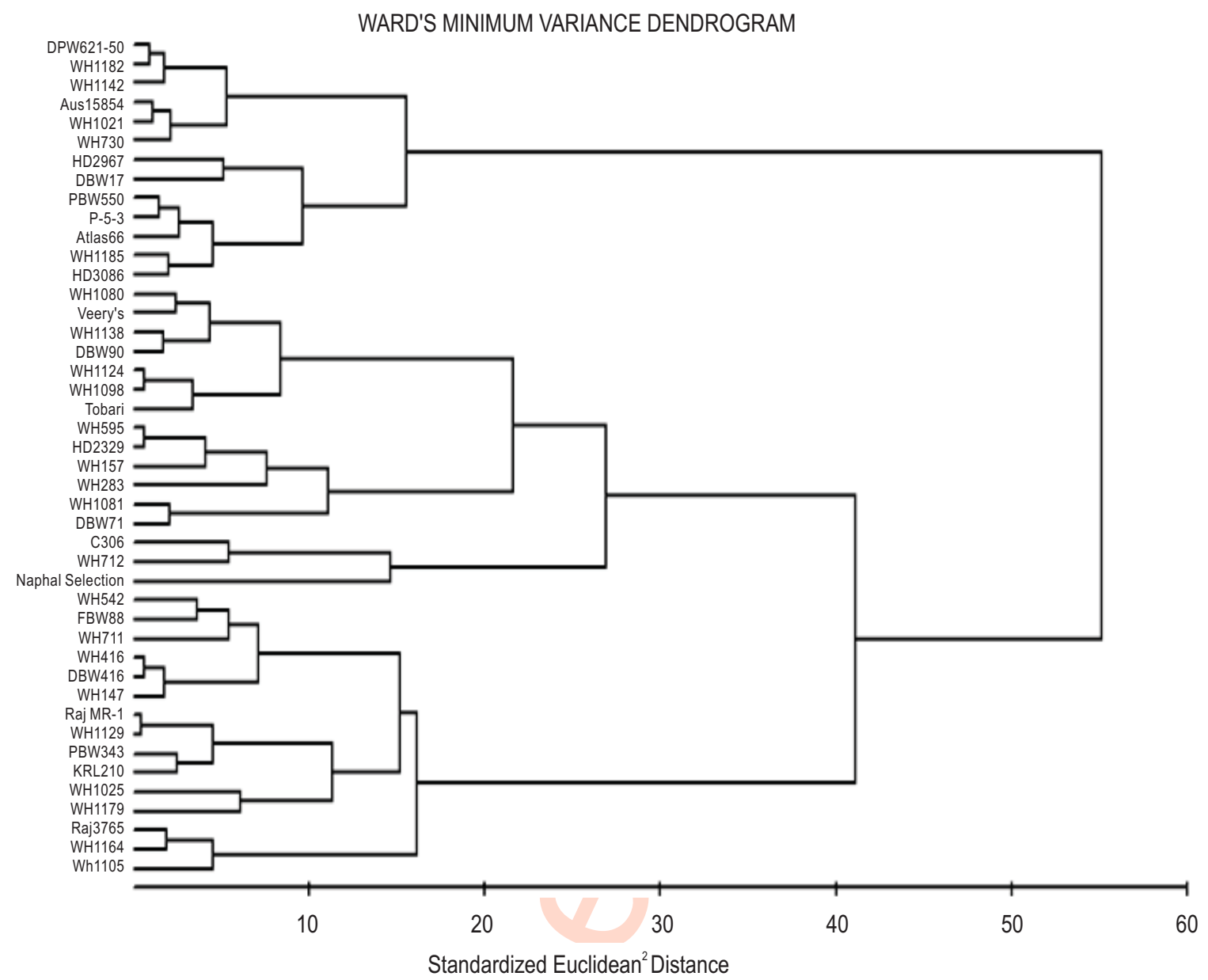

Fig. 3 : Ward's minimum variance dendrogram of advance breeding lines and cultivars based on standardized Euclidean 2 distance

primers and found that genetic similarity coefficient ranged from 0.0938 to 0.7586 , while Nasab et al. (2013) reported gene diversity statistics in the range of 0.66 to 0.94 for 37 microsatellite loci. This variation in genetic similarity coefficient values may be indicated either to the disparity in number of genotypes or SSR primers used to detect DNA variegation.

The NTSYS-PC UPGMA cluster tree analysis led to the grouping of 44 genotypes broadly into two groups at the similarity coefficient of 0.62 . The group I was very large and include 43 genotypes, while group II includes only one genotype (Tobari), which indicates that this genotype was highly diverged with respect to other genotypes and its pedigree also proved that it was an exotic cultivar. Group I, which includes 43 genotypes, was further divided into 2 clusters at similarity coefficient of 0.629 . Cluster I includes 38 genotypes, namely HD 3086, HD 2967, HD 2329, DBW 71, DBW 88, DBW 17, DBW 90, WH 1080, WH 1021, DBW 16, WH 730, WH 1105, WH 1129, WH 1142, C 306, WH 1138, WH 1179, WH 1182, WH 1124, WH 1185, Raj 3765, DPW 621-50, PBW 550, WH 283, WH 712, KRL 210, WH 1098, WH
595, Veery's, P-5-3, Naphal, Atlass 66, WH 1164, WH 1025, WH 711, WH 1081, PBW 343 and WH 542. These genotypes may have similar gene pool contributing to greater similar repetitive sequence in their ancestors. In cluster I, WH 1182 and WH 1124 were found similar, although, they had different pedigree, this may be due to the reason that present day wheat varieties have been derived from six broad genotypes, viz., Cross II-8156, Pitic 62, Sonora-64, Lerma Rojo-64, Ciano-67 and Bluebird. Cluster II consisted of only 5 genotypes, namely, WH 157, WH 416, WH 147, Aus 158854, and Raj MR-1.

Two and three dimension principal component analysis based on SSR data, showed similar clustering of 44 wheat genotypes as evident from cluster tree analysis.

Morphological traits have been studied for the estimation of genetic diversity and as selection criteria for wheat breeding (Marti et al., 2007). For quantifying the genetic divergence between a numbers of genotypes based on morphological data, Euclidean cluster analysis was employed. On the basis of relative 
magnitude of distances, 44 genotypes were grouped into 5 clusters (Fig. 3). Further, cluster pattern revealed that cluster $V$ was the largest cluster consisting of 15 genotypes which was followed by cluster I (with 13 genotypes), cluster II (with 7 genotypes), cluster III (with 6 genotypes) and cluster IV which was the smallest cluster (with 3 genotypes). Cluster I comprised of genotypes which had highest cluster mean value for grains per ear (49.49), harvest index (\%) (40.81) and grain yield per plant (g) (21.14). Cluster II had low mean value for plant height $(\mathrm{cm})$ (89.52) which was desirable in present semi-dwarf varieties, for tiller number per plant (19.08). The cluster III can be exploited for characters like 1000-grain weight (g) with highest cluster mean value (44.97). Cluster IV had highest mean value for biological yield per plant (g) (54.59) and Cluster V genotypes had lowest cluster mean value for plant height $(\mathrm{cm})$ (89.35). Thus, incorporation of genotypes from respective cluster for contrasting traits can be beneficial. Divergent parents in hybridization programme can led to recovery of transgressive segregants with high genetic yield potential in segregating generations.

Molecular variation evaluated in this study in combination with morphological characters of wheat can be useful in traditional and molecular breeding programs. Thus, microsatellite markers can be exploited as a new generation tool in studying the polymorphism and genetic diversity among cultivars and identification of parental combinations effectively to maintain maximum genetic variability in progenies.

\section{Acknowledgment}

Financial support received from the Department of Science \& Technology, New Delhi in the form of INSPIRE Fellowship is greatly appreciated by the author.

\section{References}

Abouzied, H.M., S.M.M. Eldemery and K.F. Abdellatif: SSR-based genetic diversity assessment in tetraploid and hexaploid wheat populations. British Biotechnol. J., 3, 390-404 (2013).

Anonymous: Progress Report of the All India Coordinated Wheat and Barley Improvement Project 2015-16. Crop Improvement (Eds: V. Tiwari, R. Chatrath, G. Singh, R. Tiwari, B.S. Tyagi, R. Kumar, S.K. Singh, S. Kumar, C.N. Mishra, K. Venkatesh, H.M. Mamrutha, V. Gupta, Gopalareddy, A. Verma, I. Sharma, R.K. Gupta and G.P. Singh). Vol. 1, ICAR-Indian Institute of Wheat and Barley Research, Karnal, India, p. 258 (2016).

Arora, A., S. Kundu, N. Dilbaghi, I. Sharma and R. Tiwari: Population structure and genetic diversity among Indian wheat varieties using microsatellite (SSR) markers. Austr. J. Crop Sci., 8, 1281-1289 (2014).

Bryan, G.J., A.J. Collins, P. Stephenson, A. Orry, J.B. Smith and M.D. Gale: Isolation and characterization of microsatellites from hexaploid bread wheat. Theor. Appl. Genet., 94, 557-563 (1997).

Cifci, E.A. and Yagdi: Study of genetic diversity in wheat (Triticum aestivum) varieties using random amplified polymorphic DNA (RAPD) analysis. Turk J. Field Crops, 17, 91-95 (2012).

Drikvand, R., G. Najafian, Elham and Salahvarzi: Investigation of genetic diversity of some durum wheat genotypes using SSR markers. J. Biol. Environ. Sci., 6, 24-32 (2015).

Han, B., C. Wang, Z. Tang, Y. Ren, Y. Li, D. Zhang, Y. Dong and X. Zhao: Genome-wide analysis of microsatellite markers based on sequenced database in chinese spring wheat (Triticum aestivum L.). PLOS ONE, 10, e0141540. doi:10.1371/journal.pone.0141540 (2015).

Hao, C., L. Wang, H. Ge, Y. Dong and X. Zhang: Genetic diversity and linkage disequilibrium in Chinese bread wheat (Triticum aestivum L.) revealed by SSR Markers. Plant Sci. J., 6, $772-779$ (2011).

Huang, X.Q., A. Boerner, M.S. Roeder and M.W. Ganal: Assessing genetic diversity of wheat (Triticum aestivum L.) germplasm using microsatellite markers. Theor. Appl. Genet., 105, 699-107 (2002).

Kara, K. and M.R. Knaouni: Genetic diversity of bread wheat genotypes (Triticum aestivum L.) revealed by agromorphological characteristics and microsatellite SSR markers. Int. J. Eng. Res. Tech., 6, 178-182 (2017).

Khan, M.K., A. Pandey, G. Thomas, M.S. Akkaya, S.A. Kayis, Y. Ozsensoy, M. Hamurcu, S. Gezgin, A. Topal and E.E. Hakki: Genetic diversity and population structure of wheat in India and Turkey. AoB Plants, 7, plv083 doi:10.1093/aobpla/plv083 (2015).

Kumar, S., V. Kumar, P. Kumari, Kirti, A.K. Singh and R. Singh: DNA fingerprinting and genetic diversity studies in wheat genotypes using SSR markers. J. Environ. Biol., 37, 319-326 (2016).

Ma, Z.Q., M.S. Roder and M.E. Sorrells: Frequencies and sequence characteristics of di-, tri and tetra-nucleotide microsatellites in wheat. Genome, 39,123-130 (1996).

Malik, R., R. Tiwari, A. Arora, P. Kumar, S. Sheoran, P. Sharma, R. Singh, V. Tiwari and I. Sharma: Genotypic characterization of elite Indian wheat genotypes using molecular markers and their pedigree analysis. Aust. J. Crop Sci., 7, 561-567 (2013).

Marti, J., J. Bort, G.A. Slafer and J.L. Araus: Can wheat yield be assessed by early measurements of normalized difference vegetation index? Annal. Appl. Biol., 150, 253-257 (2007).

Mir, R.R., J. Kumar, H.S. Balyan and P.K. Gupta: A study of genetic diversity among Indian bread wheat (Triticum aestivum L.) cultivars released during last 100 years. Genet. Resour. Crop Evol., 59, 717-726 (2011).

Nasab, S.S., G.M. Nejad and B. Nakhoda: Assessing genetic diversity of promising wheat (Triticum aestivum L.) lines using microsatellite markers linked with salinity tolerance. J. Plant. Mol. Breed., 1, 2839 (2013).

Panse, V.G. and P.V. Sukhatme: Statistical Method for Agricultural Workers. Indian Council of Agricultural Research, New Delhi (1978)

Parker, G.D., P.N. Fox, P. Langridge, K. Chalmers, B. Whan and P.F. Ganter: Genetic diversity within Australian wheat breeding programs based on molecular and pedigree data. Euphytica, 124, 293-306 (2002).

Roder, M.S., J. Plaschke, S.U. Konig, A. Borner, M.E. Sorrells, S.D. Tanksley and M.W. Ganal: Abundance, variability and chromosomal location of microsatellite loci in wheat. Mol. Gen. Genet., 246, 327-333 (1995).

Rohlf, F.J.: NTSYS pc numerical taxonomy and multivariate analysis system user guide. New York University, New York (2000).

Saghai-Maroof, M.A., K.M. Soliman, R.A. Jorgensen and R.W. Allad: Ribosomal DNA spacer-length polymorphism in barley, Mendelian inheritance. Chromosomal location and population dynamics. Proc. Natl. Acad. Sci. U.S.A., 81, 8014-8019(1984). 
Schuster, I., E.S.N. Vieira, G.J. Silva, F.A. Franco and V.S. Marchioro: Genetic variability in Brazilian wheat cultivars assessed by microsatellite markers. Genet. Mol. Biol., 32, 557563 (2009).

Sharma, J., N. Goyal, A. Singh, J.K. Pallavi, H. Sonah and P. Gupta: Assessment of genetic relationships among bread wheat (Triticum aestivum L. em. Thell) genotypes using microsatellite markers. Int. J.Appl. Agric. Res., 5, 575-582 (2010).

Spanic, V., H. Buerstmayr and G. Derezner: Assessment of genetic diversity of wheat genotypes using microsatellite markers. Period Biolog., 114, 37-42 (2012).

Ward, H.J.: Hierarchical grouping to optimize an objective function. J.
Amer. Stat. Ass., 58, 236-244 (1963).

Yildirim, A., O.A. Sonmezoglu, S. Gokhen, N. Kandemir and N. Aydin: Determination of genetic diversity among Turkish durum wheat landraces by micro satellites. Afr. J. Biotech., 10, 3915-3920 (2011).

Zhang, K., J. Tian, L. Zhao, B. Liu and G. Chen: Detection of quantitative trait loci for heading date based on the doubled haploid progeny of two elite Chinese wheat cultivars. Genetica, 135, 257-265(2009).

Zhang, P., S. Dreisigacker, A. Buerkert, S. Alkhanjari, A.E. Melchinger and M.L. Warburton: Genetic diversity and relationship of wheat landraces from Oman investigated with SSR markers. Genet. Resour. Crop Evol., 53, 1351-1360 (2006). 